\title{
Papillary Thyroid Carcinoma Masquerading Miliary Tuberculosis
} Maryam Hassanzad, ${ }^{1}$ Fatemeh Malek, ${ }^{1, *}$ and Mohammad Bloursaz ${ }^{1}$

${ }^{1}$ Pediatric Respiratory Diseases Research Center, National Research Institute of Tuberculosis and Lung Diseases (NRITLD), Shahid Beheshti University of Medical Sciences, Tehran, Iran

"Corresponding author: Fatemeh Malek, MD, Pediatric Respiratory Diseases Research Center, National Research Institute of Tuberculosis and Lung Diseases (NRITLD), Shahid Beheshti University of Medical Sciences, Tehran, Iran. E-mail: fmalek7721@gmail.com

Received 2017 August 15; Accepted 2017 November 06.

Keywords: Papillary Thyroid Carcinoma

\section{Dear Editor,}

A 12-year-old female was referred to our center due to respiratory distress, cough, and tachypnea since 4 months ago with suspicion of miliary TB.

The CXR showed a bilateral reticulonodular pattern and CT of the thorax revealed extensive bilateral pulmonary infiltration without pleural effusion. On examination, she was stable. Her weight corresponded to the tenth percentile for age. She had a significant bilateral cervical lym-phadenopathy approximately $2 \times 2$. Further evaluation revealed thyroid enlargement that was firm and free from surrounding tissues. The measurements were $6 \times 5$ $\mathrm{cm}$ on the right side and $7 \times 6 \mathrm{~cm}$ on the left side. Respiratory system examination revealed coarse crackles at both lungs. Tuberculin test was negative. Three samples of gastric washing for acid-fast bacilli were negative.

Further assessments confirmed the thyroid mass; hence, the patient underwent thyroidectomy. pathology was compatible with papillary thyroid carcinoma.

PTC is usually evident in young women, and the female: male incidence is greater than 5:1 in adolescents; additionally, gender difference is not prominent

in children younger than 10 years $(1,2)$. In contrast to the classical type, childhood PTC, particularly in patients younger than 10 years, maybe unencapsulated.

In PTC, metastases first are discovered in regional lymph nodes. The lung is the commonest site of metastasis (70\%), with other sites including bone (20\%), mediastinum, brain, adrenal, skin, and liver $(2,3)$. In our case, the metastases were first defined in the lungs and the patient was referred as miliary tuberculosis. The lung metastasis in PTC may present as miliary pattern or multiple or localized infiltration. Our patient presented with bilateral widespread reticulonodular formations in the radiological examination.

We suggest that broad evaluation should be done in

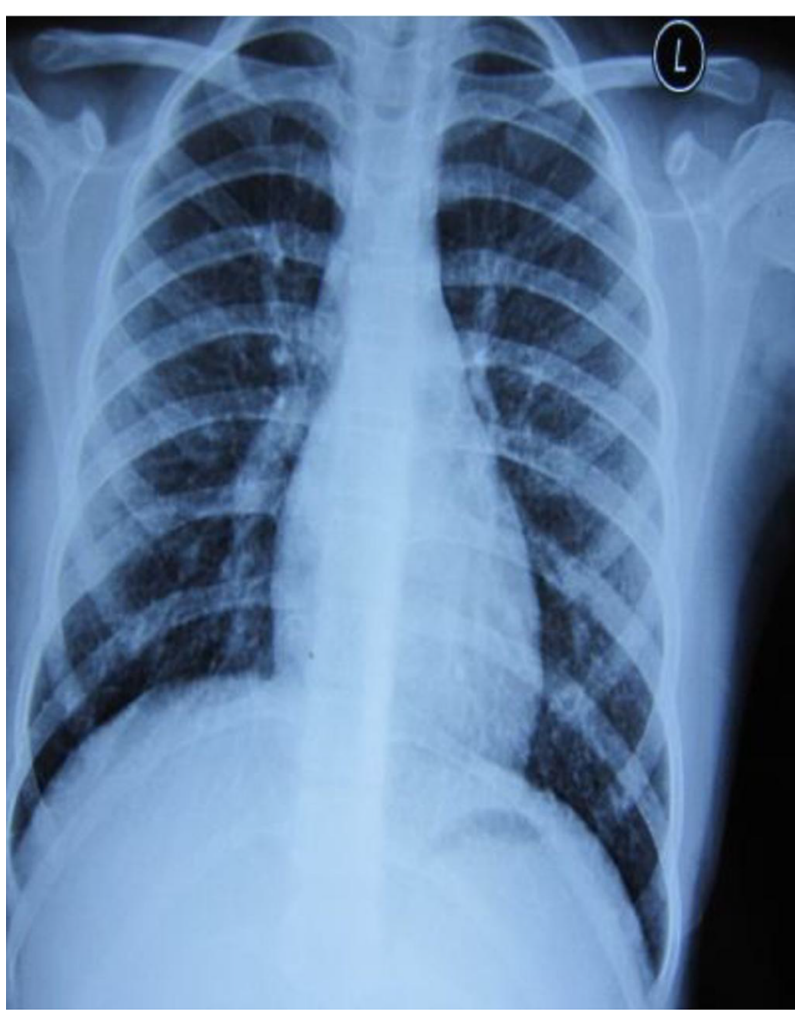

Figure 1. Bilateral Reticulonodular Pattern in CXR

case of a bilateral reticulonodular pattern of CXR. 

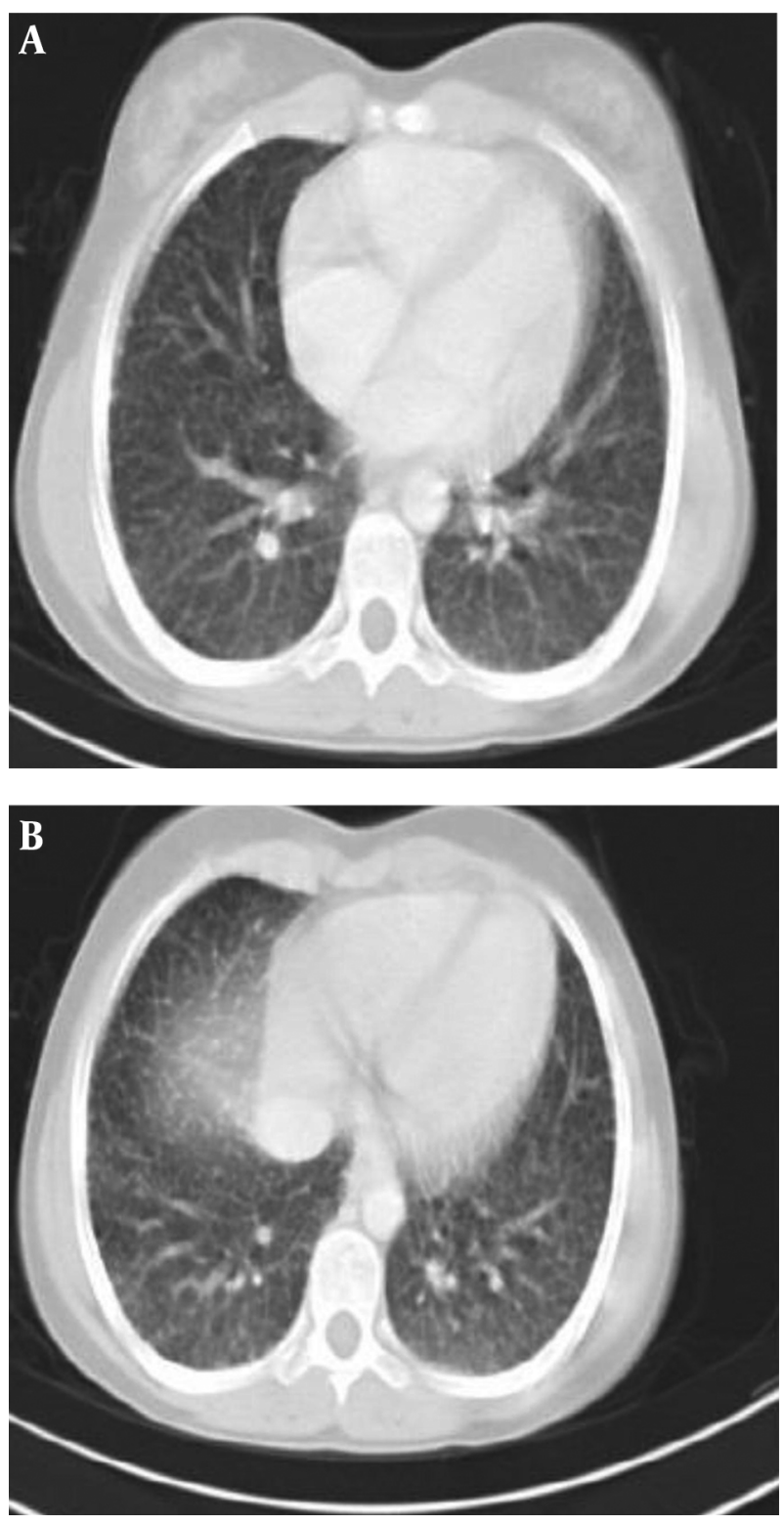

Figure 2. Bilateral Reticulonodular Pattern in CT Scan of the Lungs

\section{References}

1. Erden ES, Babayigit C, Davran R, Akin M, Karazincir S, Isaogullari $\mathrm{N}$, et al. Papillary thyroid carcinoma with lung metastasis arising from dyshormonogenetic goiter: a case report. Case Rep Med. 2013;2013:813167. doi: 10.1155/2013/813167. [PubMed: 24307906].

2. Oneill CJ, Oucharek J, Learoyd D, Sidhu SB. Standard and emerging therapies for metastatic differentiated thyroid cancer. Oncologist. 2010;15(2):146-56. doi: 10.1634/theoncologist.2009-0190. [PubMed: 20142332].

3. Song HJ, Xue YL, Xu YH, Qiu ZL, Luo QY. Rare metastases of differentiated thyroid carcinoma, pictorial review. Endocr Relat Cancer. 2011;18(5):165-74. doi: 10.1530/ERC-11-0068. [PubMed: 21632805]. 